\title{
PENGARUH KEPEMIMPINAN DAN BUDAYA ORGANISASI TERHADAP KINERJA FASILITATOR PADA PROGRAM KOTA TANPA KUMUH DI KOTA LUBUKLINGGAU
}

\section{INFLUENCE OF LEADERSHIP AND ORGANIZATIONAL CULTURE ON THE PERFORMANCE OF FACILITATOR IN CITY WITHOUT SLUM PROGRAM IN LUBUKLINGGAU CITY}

\author{
Wendy Syahputra ${ }^{1}$, Maresta Dora ${ }^{2}$ \\ Sekolah Tinggi Ilmu Ekonomi dan Bisnis Prana Putra ${ }^{1,2}$ \\ wendysyahputra@stiebipranaputra.ac.id ${ }^{1}$
}

\begin{abstract}
The relationship of these theories with the three variables under study in which a competent and good leadership owned by a leader can influence and guide the facilitator to improve performance in order to achieve the expected goals. The method used in this research is the Quantitative Method. The population in this study was all the Facilitators, the sample taken in this study was the taking of the entire population or a saturated sample of 42 people. The hypothesis can be said to be proven and tested its truth, so it can be concluded that the Leadership and Organizational Culture have a significant or partially significant effect on the performance of the Facilitators in the Office of the City without Slums Program. Furthermore, the existence of Organizational Culture which is given by the leader to the facilitator can have an impact on the working spirit of the facilitator on the work, so as to obtain the expected results. This has an impact or effect on improving the Facilitator's Performance. This result is proven by the hypothesis and research conducted by researchers in which all three variables get positive and significant results. Thus if Leadership and Organizational Culture are implemented effectively and efficiently, it can improve the Performance of Facilitators in the Slumless City Program Office.
\end{abstract}

Keywords: Leadership, Organizational Culture, Performance Facilitator.

\begin{abstract}
ABSTRAK
Hubungan teori-teori tersebut dengan ketiga variabel yang diteliti dimana dengan adanya Kepemimpinan yang berkompeten dan baik yang dimiliki oleh seorang pemimpin dapat mempengaruhi dan membimbing fasilitator untuk meningkatkan kinerja guna mencapai tujuan yang diharapkan. Metode yang digunakan dalam penelitian ini adalah Metode Kuantitatif. Populasi dalam penelitian ini seluruh Fasilitator, sampel yang diambil dalam penelitian ini adalah pengambilan populasi keseluruhan atau sampel jenuh yaitu sebanyak 42 orang. Hipotesis dapat dikatakan terbukti dan teruji kebenarannya, Sehingga dapat disimpulkan bahwa Kepemimpinan dan Budaya Organisasi berpengaruh signifikan secara parsial maupun simultan Terhadap Kinerja Fasilitator Di Kantor Program Kota Tanpa Kumuh. Selanjutnya dengan adanya Budaya Organisasi yang diberikan pimpinan terhadap fasilitator, maka dapat berdampak terhadap semangat kerja fasilitator terhadap pekerjaan, sehingga memperoleh hasil yang diharapkan. Hal ini berdampak atau berpengaruh pada peningkatan Kinerja Fasilitator. Hasil ini terbukti dengan hipotesis dan
\end{abstract}


penelitian yang dilakukan oleh peneliti dimana ketiga variabel memperoleh hasil positif dan signifikan. Dengan demikian apabila Kepemimpinan dan Budaya Organisasi diimplementasikan secara efektif dan efisien, maka dapat meningkatkan Kinerja Fasilitator di Kantor Program Kota Tanpa Kumuh.

Kata Kunci: Kepemimpinan, Budaya organisasi, Kinerja Fasilitator

\section{PENDAHULUAN}

Sumber Daya manusia merupakan asset terpenting karena perannya sebagai subjek pelaksana kebijakan dan kegiatan operasional. Sumber daya yang dimiliki itu seperti modal, metode dan mesin tidak bisa memberikan hasil optimum apabila tidak didukung oleh sumber daya manusia yang mempunyai kinerja yang optimum. Selama Pegawai bekerja di suatu organisasi secara teratur perlu diadakan evaluasi terhadap kinerjanya, apakah oleh atasannya, bagian personel atau pejabat lain maupun panitia khusus yang ditunjuk. Sumber Daya Manusia merupakan tokoh sentral dalam organisasi agar aktivitas manajemen berjalan dengan baik.

$$
\text { Menurut Wibowo, }
$$

Pengertian performance sering diartikan sebagai kinerja, hasil kerja atau prestasi kerja. Kinerja mempunyai makna yang lebih luas, bukan hanya menyatakan sebagai hasil kerja, tetapi juga bagaimana proses kerja berlangsung. Kinerja adalah tentang melakukan pekerjaan dan hasil yang dicapai dari pekerjaan tersebut. Kinerja adalah tentang apa yang dikerjakan dan bagaimana cara mengerjakannya. Kinerja merupakan hasil pekerjaan yang mempunyai hubungan kuat dengan tujuan strategis organisasi, kepada kepuasaan konsumen dan memberikan kontribusi ekonomi (Suwatno \& Doni, 2013).

Penilaian kinerja adalah suatu metode untuk membandingkan berbagai pekerjaan dengan menggunakan prosedur-prosedur formal dan sistematik untuk menentukan suatu urutan tingkat pekerjaan-pekerjaan itu melalui penentuan kedudukan dan ratio satu pekerjaan dibandingkan dengan pekerjaan yang lain. Hasil penilaian kinerja ini disebut sebagai kinerja, yang dapat dijadikan sebagai dasar untuk memberikan suatu system upah yang adil. Kata "pekerjaan" mempunyai berbagai tafsiran yang demi kejelasan dan ketepatan memerlukan definisi yang teliti (Poltak, 2012). Menurut Fahmi (2014) Penilaian kinerja adalah suatu penilaian yang dilakukan kepada pihak manajemen perusahaan baik para karyawan maupun manajer yang selama ini telah melakukan pekerjaannya. Penilaian kinerja merupakan proses mengevaluasi seberapa baik karyawan mengerjakan pekerjaan mereka ketika dibandingkan dengan satu satu set standard dan kemudian mengkomunikasikan informasi tersebut. Kepemimpinan adalah kemampuan untuk mempengaruhi kelompok menuju pencapaian sasaran (Suwatno \& Doni 2013). Kepemimpinan adalah penciptaan cara bagi orang untuk ikut berkontribusi dalam mewujudkan sesuatu yang luar biasa. Suwatno \& Doni (2013) mengemukakan bahwa kepemimpinan adalah tindakan memotivasi orang lain atau menyebabkan orang lain melakukan tugas tertentu dengan tujuan untuk mencapai tujuan spesifik. Sedangkan Suwatno \& Doni (2013) berpendapat kepemimpinan adalah sebuah persoalan kecerdasan, kelayakan untuk dipercaya, kelembutan, keberanian, dan ketegasan.

Kemampuan untuk memberikan pengaruh yang konstruktif kepada orang 
lain untuk melakukan satu usaha kooperatif mencapai tujuan yang sudah direncanakan. Suwatno \& Doni (2013) menyatakan Kepemimpinan adalah peranan dan juga suatu proses untuk mempengaruhi orang lain.

Menurut Fahmi (2014) selain Kepemimpinan, Budaya organisasi juga mempengaruhi Kinerja pegawai, Budaya Organisasi adalah suatu kebiasaan yang telah berlangsung lama dan dipakai serta diterapkan dalam kehidupan aktivitas kerja sebagai salah satu pendorong untuk meningkatkan kualitas kerja para karyawan dan manajer perusahaan. Kultur organisasi sebagai sekumpulan nilai dan norma hasil berbagi yang mengendalikan interaksi anggota organisasi satu sama lain dan dengan orang diluar organisasi. Menurut Sholihin (2019) Budaya organisasi sebagai cermin dari nilai-nilai kehidupan korporasi yang efektif dengan tujuan utama untuk menerangi dan mencerahkan visi perusahaan. Budaya organisasi yang dipahami dan dijalankan secara benar akan menghasilkan daya tahan organisasi yang kuat dan unggul.

Program Nasional Pemberdayaan Masyarakat Mandiri Perkotaan (PNPMMP) yang sekarang berganti nama manjadi Program Kota Tanpa Kumuh (KOTAKU) merupakan program yang bertujuan membantu masyarakat perkotaan khususnya di kelurahan yang ada di kota lubuklinggau mencakup kegiatan lingkungan, kegiatan sosial dan kegiatan ekonomi, KOTAKU telah lama menjalankan programnya yang bersentuhan langsung dengan masyarakat. Maksudnya, program yang dilakukan merupakan hasil dari tinjauan masyarakat masing-masing dan dilaksanakan juga oleh masyarakat sendiri, sehingga hasilnya sesuai kebutuhan prioritas masyarakat dan bertujuan mencegah suatu permukiman menjadi kumuh dan membuat permukiman yang teridentifikasi kumuh menjadi permukiman yang bebas kumuh.

Dalam menjalankan program tersebut di KOTAKU memiliki konsultan-konsultan atau istilah di KOTAKU disebut Fasilitator. Fungsi fasilitator ialah sebagai penghubung atau menjembatan antara masyarakat dengan program KOTAKU yang ada. Fasilitator bertugas membimbing, memberi pelajaran, mengarahkan masyarakat agar program yang dilakukan berjalan dengan baik yaitu sesuai keinginan masyarakat dan juga pihak KOTAKU itu sendiri. Dari sisi kinerja terlihat bahwa terkadang pekerjaan sering ditunda dalam penyelesaiannya, dikarenakan hanya beberapa orang saja yang mengerjakan pekerjaan tersebut, akan tetapi yang lain tidak diberikan sehingga hasil pekerjaan tidak sesuai dengan waktu yang ditentukan. Apabila pekerjaan diharapkan selesai pada siang hari terkadang sampai besok baru selesai dikerjakan. Hal ini disebabkan menurunnya kualitas dan kemampuan fasilitator, Kurangnya Inisiatif dan Rasa tanggung jawab terhadap pekerjaan dan tugas.

Berdasarkan uraian di atas pentingnya kinerja fasilitator agar hasil yang didapat bermanfaat dan dinilai baik, maka untuk mengetahui kinerja fasilitator ada banyak yang mempengaruhi di antaranya Kepemimpinan dan Budaya Organisasi. Adapun tujuan dari penelitian ini untuk mengetahui seberapa besar pengaruh Kepemimpinan dan Budaya Organisasi secara simultan terhadap kinerja fasilitator di Program Kota Tanpa Kumuh di Kota Lubuklinggau.

\section{METODE PENELITIAN}

Metode yang digunakan dalam penelitian ini adalah Metode Kuantitatif. Teknik pengumpulan data menggunakan Kuesioner. Objek penelitian adalah 
seluruh fasilitator Program Kota Tanpa Kumuh (KOTAKU) di Kota Lubuklinggau berjumlah 42 orang. Adapun variable yang digunakan terdiri dari 2 (dua) Variabel bebas yaitu Kepemimpinan (X1), Budaya Organisasi (X2) dan Variabel terikat yaitu Kinerja Fasilitator (Y).

Teknik analisa data yang digunakan dalam penelitian ini diantaranya uji kelayakan instrument penelirian yang terdiri dari uji validitas dan reliabilitas. Validitas adalah suatu ukuran yang menunjukan tingkat-tingkat kevalidan atau kesahihan sesuatu instrument.

Uji Validitas sebaiknya dilakukan pada setiap butir pertanyaan atau pernyataan di uji validitasnya. Hasil $r$ hitung kita bandingkan dengan $r$ table dmana $\mathrm{df}=\mathrm{n}-2$ dengan sig 5\%. Jika $\mathrm{r}$ table $<\mathrm{r}$ hitung maka valid, sedangkan uji Reliabilitas menunjuk pada satu pengertian bahwa sesuatu instrumen cukup dapat dipercaya untuk digunakan sebagai alat pengumpul data karena instrumen tersebut sudah baik.

Setalah melalui pengujian validitas dan reliabilitas selanjutnya dilakukan analisis hipotesis menggunakan regresi linerar berganda.. Penulis dibantu dengan program SPSS 17.

\section{HASIL DAN PEMBAHASAN Regresi Linear Berganda}

Adapun hasil dari perhitungan Regresi linear berganda antara Kepemimpinan dan Budaya Organisasi terhadap Kinerja Fasilitator pada Program Kota Tanpa Kumuh dapat dilihat pada table dibawah ini :

Tabel 1 Hasil Regresi Linier Berganda

\begin{tabular}{|c|c|c|c|c|}
\hline \multirow{2}{*}{\multicolumn{2}{|c|}{ Model }} & \multicolumn{2}{|c|}{ Unstandardized Coefficients } & \multirow{2}{*}{$\begin{array}{c}\begin{array}{c}\text { Standardized } \\
\text { Coefficients }\end{array} \\
\text { Beta } \\
\end{array}$} \\
\hline & & $\mathrm{B}$ & Std. Error & \\
\hline \multirow[t]{3}{*}{1} & (Constant) & 7.487 & 2.637 & \\
\hline & Kepemimpinan & .315 & .058 & .393 \\
\hline & Budaya_Organisasi & .557 & .064 & .628 \\
\hline
\end{tabular}

Hasil penelitian menunjukkan bahwa hasil penelitian Regresi Linear berganda adalah $\mathrm{Y}=7,487+0,315 \mathrm{X}_{1}+$ $0,557 \mathrm{X}_{2}$. Dari persamaan nilai fungsi regresi di atas terlihat bahwa nilai konstanta yang diperoleh adalah sebesar $\mathrm{a}=7,487$.

\section{Uji F (Simultan)}

Adapun hasil dari Uji $F$ (Simultan) antara Kepemimpinan dan Budaya Organisasi terhadap Kinerja Fasilitator pada Program Kota Tanpa Kumuh dapat dilihat pada table dibawah ini :

Tabel 2 : Hasil Uji F (Simultan)

\begin{tabular}{ccccccc}
\hline & \multicolumn{1}{c}{ Sum of } & \multicolumn{2}{c}{ Mean } \\
Model & Squares & df & Square & F & Sig. \\
\hline 1 & Regression & 977.745 & 2 & 488.873 & 182.172 & $.000^{\mathrm{a}}$ \\
\cline { 2 - 6 } & Residual & 104.659 & 39 & 2.684 & & \\
\cline { 2 - 6 } & Total & 1082.405 & 41 & & & \\
\hline \multicolumn{6}{l}{ Sumber : Data Olahan (2018) }
\end{tabular}

Berdasarkan tabel di atas, didapat bahwa nilai Fhitung yang diperoleh adalah sebesar 182,172 > Ftabel $=2,839$ dan tingkat kemaknaan secara serentak signifikan $F$ adalah 0,000. Hal ini menunjukkan bahwa secara simultan variabel bebas penelitian (Kepemimpinan dan Budaya Organisasi) memiliki pengaruh yang signifikan terhadap variabel terikat (Kinerja Fasilitator).

\section{Uji t (Parsial)}


Untuk melihat pengaruh parsial dari masing-masing variabel bebas terhadap variabel terikat dapat dijelaskan dengan menggunakan uji $t$, hasil uji $t$ secara rinci disajikan pada tabel di bawah ini:

Tabel 3 Hasil Uji T (Parsial)

\begin{tabular}{|c|c|c|c|c|c|c|}
\hline \multirow{2}{*}{\multicolumn{2}{|c|}{ Model }} & \multicolumn{2}{|c|}{$\begin{array}{l}\text { Unstandardized } \\
\text { Coefficients }\end{array}$} & \multirow{2}{*}{$\begin{array}{c}\begin{array}{c}\text { Standardiz } \\
\text { ed } \\
\text { Coefficient } \\
\text { s }\end{array} \\
\text { Beta }\end{array}$} & \multirow{3}{*}{$\frac{t}{4.847}$} & \multirow{3}{*}{$\frac{\text { Sig. }}{.000}$} \\
\hline & & \multirow{2}{*}{$\frac{B}{18.872}$} & \multirow{2}{*}{$\begin{array}{c}\begin{array}{c}\text { Std. } \\
\text { Error }\end{array} \\
3.894\end{array}$} & & & \\
\hline 1 & (Constant) & & & & & \\
\hline & $\begin{array}{l}\text { Kepemimp } \\
\text { inan }\end{array}$ & .679 & .068 & .845 & 9.994 & .000 \\
\hline
\end{tabular}

Sumber : Data Olahan (2018)

Berdasarkan hasil perhitungan uji $\mathrm{t}$ pada tabel $4.61 \mathrm{di}$ atas dapat dijelaskan, bahwa variabel Kepemimpinan (X1) terhadap Kinerja Fasilitator (Y) menunjukkan nilai thitung $=9,994$ lebih besar dari nilai ttabel $=1,684$, dengan tingkat signifikan sig. $=0,000$. Hal ini berarti bahwa secara parsial variabel

Kepemimpinan (X1) memiliki pengaruh yang signifikan terhadap Kinerja Fasilitator (Y) Di Kantor Program Kota Tanpa Kumuh Kota Lubuklinggau

Tabel 4 Hasil Uji t (Parsial)

\begin{tabular}{|c|c|c|c|c|c|c|}
\hline & \multirow[b]{2}{*}{ Model } & & $\begin{array}{l}\text { Unstandardize } \\
\text { d Coefficients } \\
\end{array}$ & $\begin{array}{c}\text { Standardi } \\
\text { zed } \\
\text { Coefficie } \\
\text { nts }\end{array}$ & \multirow[t]{2}{*}{ i } & \multirow[b]{2}{*}{ Sig. } \\
\hline & & B & $\begin{array}{l}\text { Std. } \\
\text { Error }\end{array}$ & Beta & & \\
\hline 1 & (Constant) & 10.986 & 3.357 & & 3.273 & .002 \\
\hline & $\begin{array}{c}\text { Budaya_Or } \\
\text { ganisasi }\end{array}$ & .809 & .058 & .911 & 13.939 & .000 \\
\hline
\end{tabular}

Sumber : Data Olahan (2018)

Berdasarkan hasil perhitungan

uji $\mathrm{t}$ pada tabel $4.62 \mathrm{di}$ atas dapat dijelaskan, bahwa variabel Kepemimpinan (X1) terhadap Kinerja Fasilitator (Y) menunjukkan nilai thitung $=13,939$ lebih besar dari nilai ttabel $=1,684$, dengan tingkat signifikan sig. $=0,000$. Hal ini berarti bahwa secara parsial variabel Kepemimpinan (X1) memiliki pengaruh yang signifikan terhadap Kinerja Fasilitator (Y) Di Kantor Program Kota Tanpa Kumuh Kota Lubuklinggau

Hubungan teori-teori tersebut dengan ketiga variabel yang diteliti dimana dengan adanya Kepemimpinan yang berkompeten dan baik yang dimiliki oleh seorang pemimpin dapat mempengaruhi dan membimbing fasilitator untuk meningkatkan kinerja guna mencapai tujuan yang diharapkan. Selanjutnya dengan adanya Budaya Organisasi yang diberikan pimpinan terhadap fasilitator, maka dapat berdampak terhadap semangat kerja fasilitator terhadap pekerjaan, sehingga memperoleh hasil yang diharapkan. Hal ini berdampak atau berpengaruh pada peningkatan Kinerja Fasilitator. Hasil ini terbukti dengan hipotesis dan penelitian yang dilakukan oleh peneliti dimana ketiga variabel memperoleh hasil positif dan signifikan. Dengan demikian apabila Kepemimpinan dan Budaya Organisasi diimplementasikan secara efektif dan efisien, maka dapat meningkatkan Kinerja Fasilitator di Program Kota Tanpa Kumuh.

Kondisi diatas didukung oleh penelitian Lina (2014) menunjukan bahwa kepemimpinan secara parsial berpengaruh signifikan terhadap Kinerja pegawai biro universitas muhamadiyah sumatera, sedangkan Budaya Organisasi berpengaruh tidak signifikan terhadap kinerja pegawai biro UMSU. Kepemimpinan memiliki arah yang positif terhadap kinerja sedangkan Budaya Organisasi memiliki arah negative. Kepemimpinan dan Budaya Organisasi secara serempak berpengaruh terhadap Kinerja Pegawai biro UMSU. Kepemimpinan dan Budaya Organisasi 
kurang kuat untuk mempengaruhi Kinerja pegawai biro UMSU. Sistem Reward tidak mempengaruhi hubungan antara Kepemimpinan dan Budaya Organisasi dengan Kinerja Pegawai biro UMSU. Hal ini dimungkinkan karena Reward yang diberikan kepada Pegawai biro UMSU bukan berdasarkan beban kerja namun berdasarkan masa kerja, golongan dan jabatan serta tingkat kehadiran pegawai.

Kemudian penelitian Farisy (2014) yang menyebutkan bahwa budaya organisasi berpengaruh secara positif dan signifikan terhadap kinerja karyawan dan komitmen organisasional berpengaruh secara positif dan signifikan terhadap kinerja karyawan. Variabel budaya organisasi, motivasi dan komitmen organisasional koefisien regresi bertanda postitif $(+)$ menandakan hubungan yang searah, dengan kata lain budaya organisasi, motivasi dan komitmen organisasional akan meningkatkan kinerja karyawan pada rumah makan geole. Korelasi atau hubungan antara budaya organisasi, motivasi dan komitmen organisasional dengan kinerja karyawan rumah makan geole adalah sangat kuat sebesar $(\mathrm{r}=0,862)$ dan koefisien determinasi atau angka $\mathrm{R}$ square adalah sebesar 0,743 .

Sejalan dengan penelitian Junaidi \& Susanti (2019) terdapat pengaruh positif dan signifikan gaya kepemimpinan terhadap kinerja pegawai pada UPTD Baltekkomdik Dinas Pendidikan Provinsi Sumatera Barat secara parsial. 2. Terdapat pengaruh positif dan signifikan budaya organisasi terhadap kinerja pegawai pada UPTD Baltekkomdik Dinas Pendidikan Provinsi Sumatera Barat secara parsial. Begitupun dengan penelitian Reni \& Syamsir (2019) penelitian ini menunjukkan bahwa variabel budaya organisasi, baik secara simultan ataupun secara parsial, berpengaruh secara signifikan terhadap kinerja pengelolaan keuangan nagari di Kabupaten Tanah Datar. Dari hasil penelitian ini dapat disimpulkan bahwa variabel budaya organisasi baik secara simultan maupun parsial berpengaruh positif terhadap kinerja pengelolaan keuangan nagari di Kabupaten Tanah Datar. oleh karena itu, untuk lebih meningkatkan kinerja aparatur nagari di Kabupaten Tanah Datar disarankan dalam pengelolaan keuangan nagari lebih meningkatkan budaya organisasi, dikarenakan dari beberapa penelitian yang telah dilakukan oleh peneliti lainnya membuktikan bahwa budaya organisasi yang baik akan memberikan dampak yang baik terhadap kinerja pegawai.

\section{PENUTUP \\ Simpulan}

Berdasarkan hasil analisis data dan pembahasan yang telah diuraikan pada bab sebelumnya, maka dapat disimpulkan bahwa :

1. Kepemimpinan Dan Budaya Organisasi berpengaruh Signifikan secara simultan terhadap Kinerja Fasilitator Kantor Program Kota Tanpa Kumuh Di Kota Lubuklinggau

2. Kepemimpinan berpengaruh Signifikan secara Parsial terhadap Kinerja Fasilitator Kantor Program Kota Tanpa Kumuh Di Kota Lubuklinggau

3. Budaya Organisasi berpengaruh signifikan secara parsial terhadap Kinerja Fasilitator Kantor Program Kota Tanpa Kumuh Di Kota Lubuklinggau

\section{Saran}

1. Kinerja Fasilitator

Kinerja Fasilitator harus selalu ditingkatkan supaya visi dan misi organsisasi dapat terlaksana dan tercapai sesuai yang diharapkan. Supaya kinerja Fasilitator dapat 
ditingkatkan dengan baik, Hal ini sudah terbukti dalam penelitian ini dimana semua hipotesis yang di uji mendapatkan hasil nilai yang positif dan signifikan serta terbukti kebenarannya.

2. Kepemimpinan

Bagi obyek penelitian, hendaknya pemimpin lebih terbuka terhadap semua fasilitator. Dapat menjadi teladan bagi semua fasilitator. Selalu membimbing dan mengarahkan pada hal yang positif. Mengayomi dan memperhatikan serta memberi petunjuk serta solusi jika ada permasalahan. Selalu menerima masukan-masukan dari fasilitator, tetapi tegas dalam bertindak dan mengambil keputusan.

3. Budaya Organisasi

Bagi obyek penelitian, hendaknya selalu memberikan tanggung jawab terhadap pekerjaan sehingga norma dan nilai-nilai yang dimiliki berguna meningkatkan kinerja fasilitator.

\section{DAFTAR PUSTAKA}

Lina, D. (2014). Analisis pengaruh kepemimpinan dan budaya organisasi terhadap kinerja pegawai dengan sistem reward sebagai variabel moderating. Universitas Muhammadiyah, Sumatera Utara.

Farisy, H. (2014). Analisis pengaruh Budaya Organisasi, Motivasi dan Komitmen Organisasional Terhadap Kinerja Karyawan Pada Sektor Usaha Rumah
Makan. Universitas Diponegoro, Semarang.

Fahmi, I. (2014). Manajemen Teori, Kasus dan Solusi. Bandung: Alfabeta.

Junaidi, R., \& Susanti, F. (2019). Pengaruh Gaya Kepemimpinan Dan Budaya Organisasi Terhadap Kinerja Pegawai Pada UPTD Baltekkomdik Dinas Pendidikan Provinsi Sumatera Barat.

Reni, M. (2019). Pengaruh Budaya Organisasi terhadap Kinerja Aparatur Nagari dalam Pengelolaan Keuangan Nagari di Kabupaten Tanah Datar. Jurnal Administrasi Negara, 25(1), 7288

Sholihin, M. (2019). Analisis Pengaruh Kepemimpinan, Budaya Organisasi, dan Kompensasi, terhadap Kinerja Karyawan AMA YPK Yogyakarta dengan Motivasi Kerja sebagai Variabel Intervening. Albama, 9(2), 95134.

Poltak, S.,L. (2012). Kinerja Pegawai Teori Pengukuran dan Implikasi. Jakarta : Graha ilmu

Suwatno \& Donni. (2013). Manajemen SDM dalam Organisasi Public dan Bisnis. Bandung: Alfabeta.

Sujarweni Wratna. 2015. SPSS untuk Penelitian. Yogyakarta: Pustaka Baru Press

Wibowo. (2014). Perilaku dalam Organisasi. Jakarta: PT. Raja Grafindo Persada. 